\title{
Preventive Administration of the Heat Shock Protein Hsp70 Relieves Endotoxemia-Induced Febrile Reaction in Pigeons (Columba livia) and Rats
}

\author{
K. V. Lapshina ${ }^{a, *}$, I. V. Guzhova ${ }^{b}$, and I. V. Ekimova ${ }^{a}$ \\ ${ }^{a}$ Sechenov Institute of Evolutionary Physiology and Biochemistry, Russian Academy of Sciences, \\ St. Petersburg, Russia \\ ${ }^{b}$ Institute of Cytology, Russian Academy of Sciences, St. Petersburg, Russia \\ *e-mail: ksenia.lapshina@gmail.com
}

Received April 28, 2021

Revised June 17, 2021

Accepted June 23, 2021

\begin{abstract}
The stress-inducible $70 \mathrm{kDa}$ heat shock protein (Hsp70) can exert a protective effect on endotoxemia and sepsis due to its ability to interact with immune cells and modulate the immune response. However, it remains unknown whether Hsp70 is able to relieve endotoxemia-induced fever. We carried out a comparative study of the effects of preventive administration of the human recombinant Hsp70 (HSPA1A) on lipopolysaccharide (LPS)-induced endotoxemia in pigeons and rats with preimplanted electrodes and thermistors for recording the thermoregulation parameters (brain temperature, peripheral vasomotor reaction, muscular contractile activity). Additionally, we analyzed the dynamics of the white blood cell (WBC) count in rats under the same conditions. It was found that preventive administration of Hsp70 relieves the LPS-induced febrile reaction in pigeons and rats and accelerates the restoration of the WBC count in rats. The data obtained suggest that these warm-blooded animals share a common physiological mechanism that underlies the protective effect of Hsp70.
\end{abstract}

DOI: $10.1134 / \mathrm{S} 0022093021050082$

Keywords: heat shock protein $70 \mathrm{kDa}$, endotoxemia, brain temperature, white blood cells, pigeon, rat

Abbreviations: Hsp70 - heat shock protein $70 \mathrm{kDa}$; IL-1 $\beta$-interleukin-1 $\beta$; IL-6-interleukin-6; $\mathrm{PGE}_{2}$ - prostaglandin $\mathrm{E}_{2}$; TLR-Toll-like receptors; TNF- $\alpha$-tumor necrosis factor alpha; LPSlipopolysaccharide; MCA-muscle contractile activity; $T_{\mathrm{br}}-$ brain temperature; $T_{\mathrm{sk}}$-skin temperature; EMG-electromyogram

\section{INTRODUCTION}

Endotoxemia is a condition caused by an increase in the blood level of lipopolysaccharide
(LPS), which is the cell wall-derived endotoxin of Gram-negative bacteria. First of all, LPS affects the functions of immunocompetent and vascular endothelial cells, leading to the activation of the 
immune system, increased synthesis of proinflammatory cytokines, development of a febrile reaction (fever), functional changes in the nervous, endocrine and other systems of the organism [1-3]. Fever is an ancient protective and adaptive mechanism, which is characteristic of ectothermic and endothermic vertebrates and aimed at providing optimal conditions for the functioning of the immune system and elimination of the pathogen [2, 4]. In ectothermic animals, the development of the immune response is accompanied by a behavioral fever, which makes these animals to choose a warmer place in order to increase their body temperature [2, 4]. In endothermic animals (mammals and birds), a controlled increase in body temperature, induced by LPS or other pathogens, occurs due to heat transfer limitation via peripheral vasoconstriction and an increase in shivering and non-shivering thermogenesis [5-8]. It should be noted that when studying changes in thermoregulation during endotoxemia and other conditions accompanied by a fever, the main focus is usually on the assessment of body temperature, while much less attention is paid to the brain temperature $\left(T_{\mathrm{br}}\right)$. A number of literature data indicate that an increase in $T_{\mathrm{br}}$ during hyperthermia and LPS-induced endotoxemia can increase the permeability of the blood-brain barrier, affect the activity of neurons and brain metabolism, and enhance the production of beta-amyloid [9-13]. It is assumed that an increase in $T_{\mathrm{br}}$ is especially critical for patients with craniocerebral traumas, ischemic and hemorrhagic strokes, as well as young children with a propensity to febrile seizures $[14,15]$. Such a scenario can be dangerous for septic patients with a chronic febrile reaction, for example, during an increase in the blood LPS level and the presence of bacteremia or the development of a "cytokine storm" and viral sepsis, which often occur in severe cases of SARS-coV-2 infection [16, 17].

The available literature data indicate that LPS-induced endotoxemia in members of diverse animal groups (mammals, birds, fish, echinoderms) increases the expression of the stressinducible heat shock protein with a molecular weight of $70 \mathrm{kDa}$ (HSP70) in various tissues [1822]. Hsp70 refers to the evolutionary ancient chaperone system, which has a protective effect at cellular and organismal levels against various stress factors and is characterized by an extremely conserved structure [23]. Hsp70 is able to enter the systemic circulation and modulate the activity of immunocompetent cells; however, the mechanisms of its interaction with various types of cells have not yet been fully understood. It was believed that extracellular Hsp70, dubbed a "chaperokine", can act as an alarm signal due to its interaction with various receptors on monocytes/ macrophages, dendritic cells and neutrophils, such as Toll-like receptors (TLR2 and TLR4), CD91, CD40, Lox-1, etc., causing thereby the production of pro-inflammatory cytokines and NO, and also participating in antigen presentation [24-27]. Intravenous administration of exogenous Hsp70 helps reduce mortality in sepsis, corrects some hemodynamic and coagulation parameters, normalizes bilirubin and creatinine blood levels; in in vitro experiments, it reduces NO production by macrophages, decreases the generation of reactive oxygen species and partially normalizes neutrophil apoptosis in a model of endotoxin sepsis [28-31]. The above data attest to the ability of exogenous Hsp70 to influence immune response parameters and exert a protective effect in sepsis models, however, they do not allow concluding whether, in this case, the changes in body temperature, peripheral vasomotor reaction, and shivering thermogenesis, characteristic of the effect of LPS, are also corrected. Studies addressing the effect of exogenous Hsp70 on thermoregulation parameters during febrile reactions have not yet been carried out. Previously, it was shown that exogenous Hsp70, when delivered into the cerebrospinal fluid, is able to cause a decrease in $T_{\mathrm{br}}$, shivering thermogenesis, and heart rate in pigeons under control conditions $[32,33]$. These changes were associated with an increase in the duration of episodes and total time of slow-wave sleep, which has an anti-stress function. These data provided the rationale for studying the effects of exogenous Hsp70 on thermoregulation parameters of the febrile response and indicators of systemic inflammation (leukocytosis) in avian (pigeons Columba livia) and mammalian (Wistar rats) models of endotoxemia.

A comparative physiological investigation of 
Hsp70 effects in endotoxemia will help elucidate the contribution of the stress-inducible protein Hsp70 to the regulatory mechanisms of the endotoxemia-induced febrile response and reveal common and specific patterns in the manifestation of putative protective effects of Hsp70 under the effect of bacterial endotoxins.

The goal of this study was to carry out a comparative analysis of the effects of exogenous Hsp70 on febrile reaction parameters, such as $T_{\mathrm{br}}$, peripheral vasomotor response, muscle contractile activity (MCA), and white blood cell (WBC) count, in LPS-induced endotoxemia in pigeons Columbia livia and Wistar rats.

\section{MATERIALS AND METHODS}

Animals. Electrophysiological experiments were carried out on adult male and female pigeons Columba livia weighing 350-420 g and male Wistar rats weighing $280-320 \mathrm{~g}$. WBC count was performed on male Wistar rats of the same weight and age. Animals intended for electrophysiological experiments, 7-10 days prior to surgery, were placed in a sound- and lightproof experimental chamber in order to let them adapt to the maintenance conditions $(12 \mathrm{~h}$ light/12 h dark photoperiod, temperature $23 \pm 11^{\circ} \mathrm{C}$ ) During the experiment, the animals were in a transparent organic-glass cage. The distribution of pigeons into experimental groups was carried out by simple randomization, while rats were distributed based on stratified randomization using the open field test and the assessment of rats' response to handling. Animals that demonstrated high exploratory activity and low anxiety level were selected and distributed into experimental groups.

The inactive phase of the day was dark for pigeons and light for rats. Experiments on pigeons were started $4 \mathrm{~h}$ before the onset of the dark phase of the day, while on rats they commenced at the beginning of the light phase. The rats intended for WBC count were kept in a vivarium at a temperature of $23 \pm 1^{\circ} \mathrm{C}$. Food and water were available ad libitum. All manipulations with animals were carried out in compliance with the regulations of the Basel Declaration and protocol approved by the Ethics Committee of the Sechenov Institute of Evolutionary Physiology and Biochemistry
$(\mathrm{IEPhB})$ in accordance with national and international requirements.

Reagents. The Escherichia coli LPS endotoxin (0111:B4, Sigma Aldrich, USA) was used to induce endotoxemia in pigeons and rats. LPS was dissolved in apyrogenic $0.9 \%$ isotonic physiological saline and injected intravenously (i.v.) at a dose of $100 \mu \mathrm{g} / \mathrm{kg}$ in a volume of no more than $0.2 \mathrm{~mL}$.

The purified recombinant human heat shock protein Hsp70 (HSPA1A) was obtained from the extract of E. coli transformed with a pMSHsp70 plasmid. Hsp70 was isolated by ion exchange chromatography using DEAE Sepharose (GE Healthcare) with subsequent ATP affinity chromatography using ATP agarose (Sigma, USA). Next, using a polymyxin-B gel (Sigma, USA), the bacterial LPS admixture was removed. The amount of LPS in the purified protein solution was estimated using a LALA E-Toxate test (Sigma Aldrich, USA). The final Hsp70 protein solution contained less than $0.5 \mathrm{EU} / \mathrm{mg}$ LPS $[34,35]$. The resultant preparation was dissolved in saline and administered i.v. to animals 15 min before LPS (or control solution) administration at a dose of $85 \mu \mathrm{g} / \mathrm{kg}$ in a volume of no more than $0.1 \mathrm{~mL}$.

To exclude the influence of contaminants (mainly LPS) in the Hsp70 preparation on experimental results, a series of experiments was carried out using thermodenatured Hsp70 (Hsp70den) at the same dose. For this, Hsp70 was heated in a water bath to $100^{\circ} \mathrm{C}$ for $5 \mathrm{~min}$.

As a control solution, the animals were injected with saline used as a vehicle for LPS, Hsp70 and Hsp70den preparations. Saline was injected in a volume of 0.1 and $0.2 \mathrm{~mL}$ as a control to Hsp70 and LPS, respectively.

Experimental design. In order to analyze and compare the effect of Hsp70 on the LPS-induced dynamics of thermoregulation parameters, the following series of studies with i.v. administration of reagents at the above doses were carried out on pigeons $(n=6)$ and rat $(n=6)$ :

(1) control group, saline (i.v.), twice at a 15-min interval;

(2) saline (i.v.), $15 \mathrm{~min}$ before LPS (i.v.);

(3) Hsp70 (i.v.), 15 min before saline (i.v.);

(4) Hsp70 (i.v.), 15 min before LPS (i.v.).

In order to exclude the effect of residual LPS 
contamination of Hsp70 on physiological parameters in endotoxemia, a series of experiments was carried out on pigeons $(n=5)$ and rats $(n=5)$ using Hsp70den at the same dose.

To study the number of leukocytes (WBC count), blood was sampled from the rat caudal vein $1 \mathrm{~h}$ and $5 \mathrm{~h}$ after the administration of control solutions and Hsp70 and LPS preparations, as well as preventive Hsp70 administration prior to LPS. The reagents were administered at the same dose and in the same volume as in the case of studying electrophysiological parameters. This series of experiments included the following groups:

(1) control group, saline (i.v.), twice at a 15-min interval, before LPS (i.v.) $(n=8)$; $8)$; $8)$;

(2) saline (i.v.), $15 \mathrm{~min}$ before LPS (i.v.) $(n=$

(3) Hsp70 (i.v.), $15 \mathrm{~min}$ before saline (i.v.) $(n=$ $8)$;

(4) Hsp70 (i.v.), 15 min before LPS (i.v.) $(n=$

(5) Hsp70den (i.v.), 15 min before saline (i.v.) $(n=6)$

(6) Hsp70den (i.v.), 15 min before LPS (i.v.) $(n=6)$.

Surgical manipulations were carried out under general anesthesia using zoletil 100 (tiletamine hydrochloride + zolazepam; Virbac, Carros, France): $55 \mathrm{mg} / \mathrm{kg}$ to pigeons and $85 \mathrm{mg} / \mathrm{kg}$ to rats.

Changes in $T_{\mathrm{br}}$ and skin temperature $\left(T_{\mathrm{sk}}\right)$ were assessed using miniature thermistors (BetaTherm cat $2 \mathrm{~K} 7 \mathrm{MCD} 1,0.46 \mathrm{~mm}$ in diameter, $1.5 \mathrm{k} \Omega$ resistance, USA). In pigeons, a mini thermistor for measuring $T_{\mathrm{br}}$ was implanted above the hypothalamic area according to the following coordinates: $9 \mathrm{~mm}$ rostral to the zero point, $2 \mathrm{~mm}$ lateral to the midline, and $6 \mathrm{~mm}$ below the skull surface [36]. In rats, a mini thermistor was implanted at the following coordinates: $0.5 \mathrm{~mm}$ caudal to the bregma, $2.5 \mathrm{~mm}$ lateral to the midline, and $5 \mathrm{~mm}$ below the skull surface [37]. A mini thermistor for registering $T_{\mathrm{br}}$ in both pigeons and rats was attached to the skull surface using Akrodent selfhardening dental plastic (Stoma, Ukraine). Mini thermistors to record $T_{\text {sk }}$ (to assess the peripheral vasomotor reaction) were fixed on the unfeathered part of the pigeon leg and at the base of the rat tail. To record an electromyogram (EMG), hook-shaped gilded electrodes were implanted into the pectoral muscle of pigeons and cervical muscle of rats. The wires from the mini-thermistors and electrodes were pulled beneath the skin to the point where a connector was attached. In pigeons, the wires from the implanted electrodes and mini thermistors were pulled beneath the skin and connected to a microcircuit, a miniature "backpack" (15 g) that was put on the bird's back. In rats, connectors for cable connection were installed on the head and fixed with Acrodent plastic. The wires from EMG-recording electrodes and $T_{\text {sk }}$ were also pulled beneath the skin and connected to a common connector. The signals from the "backpack" or head connector were switched to a cable traveling to a preamplifier, and then, through an analog processing and digitizing unit, fed into a computer for archiving and processing. The presence of an electrical rotary joint prevented the twisting of the wires and allowed the animals to move freely. The experiments began after complete postoperative recovery of animals (after 12-14 days).

Signal processing. The electrophysiological data array was recorded for $24 \mathrm{~h}$ in pigeons and $12 \mathrm{~h}$ in rats. The original computer system SASR-8800 (USA) was used to record and analyze electrophysiological parameters [38]. The primary signal amplification (by a factor of 100) was carried out in a preamplifier. Then, the signals were fed into the analog processing unit for further amplification. For this, an analog-to-digital converter with 8 analog inputs, an input voltage range of $\pm 5 \mathrm{~V}$, and a $0.01 \%$ noise level was used. The microcomputer sampled each signal 120 times per second using a 12-bit ADC simulator. The full-scale voltage range for the electrodes was $\pm 1 \mathrm{mV}$. The EMG frequency range was $60-1000 \mathrm{~Hz}$, with EMG signals being averaged in such a way as to give 10 measurements per second. All the obtained averages were stored as binary integers with a specific sign and a resolution of $0.25 \mathrm{mV}$ [38]. The experimental setup and computer software enabled a temperature to be measured with an accuracy of $0.01^{\circ} \mathrm{C}$. An increase in the temperature measurement accuracy was achieved by careful plotting a calibration curve. The thermistors were calibrated over a wide temperature 
range, and each temperature point was obtained by averaging 10 measurements per second.

Electrophysiological data were processed using a set of programs developed previously by D. Ross (University of Tallahassee, USA) [38] and A.L. Zimin (IEPhB, St. Petersburg). In our experiments, average $T_{\mathrm{br}}$ and $T_{\mathrm{sk}}$ were calculated for $30 \mathrm{~min}$. To assess the MCA level, EMG, the amplitude of which was proportional to the degree of muscle tension and the distance between the lead electrodes, was processed. Using the software, the mean integrated EMG of the pectoral and cervical muscles was calculated for $1 \mathrm{~h}$.

White blood cell count. Total WBC count was performed using a Goryaev chamber. WBC nuclei were visualized by $3 \%$ acetic acid with Methylene blue. To count the number of WBCs, blood was diluted 10-fold.

Statistics. Data were statistically processed and illustrations were prepared using GraphPad Prizm 8 . To check the normal distribution, the ShapiroWilk test was used. Changes in $T_{\mathrm{br}}, T_{\mathrm{sk}}$, and MCA was analyzed using a repeated measures ANOVA. One-way ANOVA for independent samples (with post-hoc analysis using the Tukey's test) was used to process the WBC count data. Data in the figures are presented as the mean \pm standard error of the mean $(M \pm S E M)$.

\section{RESULTS}

\section{Effect of Hsp 70 on thermoregulation parameters during endotoxemia in pigeons and rats}

Our study showed that intravenous Hsp70 administration caused no changes in the $T_{\mathrm{br}}$, peripheral vasomotor response, and MCA compared to the control in both pigeons and rats (Figs. 1a-1f).

LPS administration caused the development of fever in pigeons, as manifested in an increase in $T_{\text {br }}$ compared to the control during the period from the 3rd to 8th hours by an average of $1 \pm$ $0.1^{\circ} \mathrm{C}(p<0.05)$ (Fig. 1a). During the first $3.5 \mathrm{~h}$, a decrease in $T_{\text {sk }}$ by an average of $1.7 \pm 0.2^{\circ} \mathrm{C}(p<$ 0.05 ) was revealed, indicating the development of vasoconstriction leading to a limitation of heat transfer and contributing to an increase in $T_{\mathrm{br}}$ (Fig. 1b). $5.5 \mathrm{~h}$ after LPS administration, $T_{\mathrm{sk}}$ increased by an average of $1.9 \pm 0.2^{\circ} \mathrm{C}(p<0.05)$, indicating that vasoconstriction was replaced by vasodilation, which promoted an increase in heat dissipation. In addition, an increase in $T_{\mathrm{br}}$ during endotoxemia was accompanied by an increase in MCA by an average of $73 \%(p<0.05)$ compared to the control level, indicative of an increase in heat production (Fig. 1c).

At the end of the active phase of the day, $T_{\mathrm{br}}$ in rats was, on average, $2^{\circ} \mathrm{C}$ lower than in pigeons (Fig. 1d). Upon LPS administration, an increase in $T_{\mathrm{br}}$ (by an average of $1.1 \pm 0.08^{\circ} \mathrm{C}, p<0.05$ ) began in rats by $1 \mathrm{~h}$ earlier than in pigeons and persisted for the next $5 \mathrm{~h}$ (Fig. 1d). The increase in $T_{\text {br }}$ was accompanied by a change in $T_{\mathrm{sk}}$ with a similar dynamics, however, the period of vasoconstriction development in rats was shorter than in pigeons (within $2 \mathrm{~h}$ ), while the vasodilation period, on the contrary, was longer (from the 3rd to 7 th hours) (Fig. 1e). Like in pigeons, in rats exposed to LPS, MCA intensified by $82 \%$ ( $p<$ $0.05)$, which contributed to an increase in heat production (Fig. 1f).

Preventive administration of Hsp70 to pigeons relieved LPS-induced fever; an increase in $T_{\text {br }}$ by an average of $0.52 \pm 0.06^{\circ} \mathrm{C}(p<0.05)$ was observed only for $1 \mathrm{~h}$ (Fig. 1a). Hsp70 application did not prevent the development of peripheral vasoconstriction in pigeons, but led to a reduced duration of the vasodilation period (Fig. 1b). In addition, Hsp70 completely eliminated the LPS-induced enhancement of MCA, which could contribute to a decrease in heat production and a severity of the febrile reaction (Fig. 1c).

In rats, preventive Hsp70 administration under endotoxemic conditions led to a decrease in the

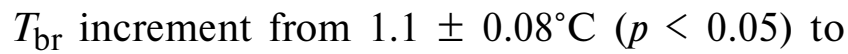
$0.56 \pm 0.05^{\circ} \mathrm{C}(p<0.05)$ (Fig. 1d); however, the period of increasing $T_{\mathrm{br}}$ in rats remained by $2.5 \mathrm{~h}$ longer than in pigeons (Fig. 1d). Hsp70 did not eliminate the development of peripheral vasoconstriction, characteristic of the effect of LPS, however, the duration of the vasodilation period decreased (Fig. 1e). In rats, by contrast to pigeons, Hsp70 did not prevent the development of LPS-induced enhancement of MCA, but promoted a reduction in the period of increasing this parameter compared to the effect of LPS alone (Fig. 1f).

Despite the fact that after isolation Hsp70 was 

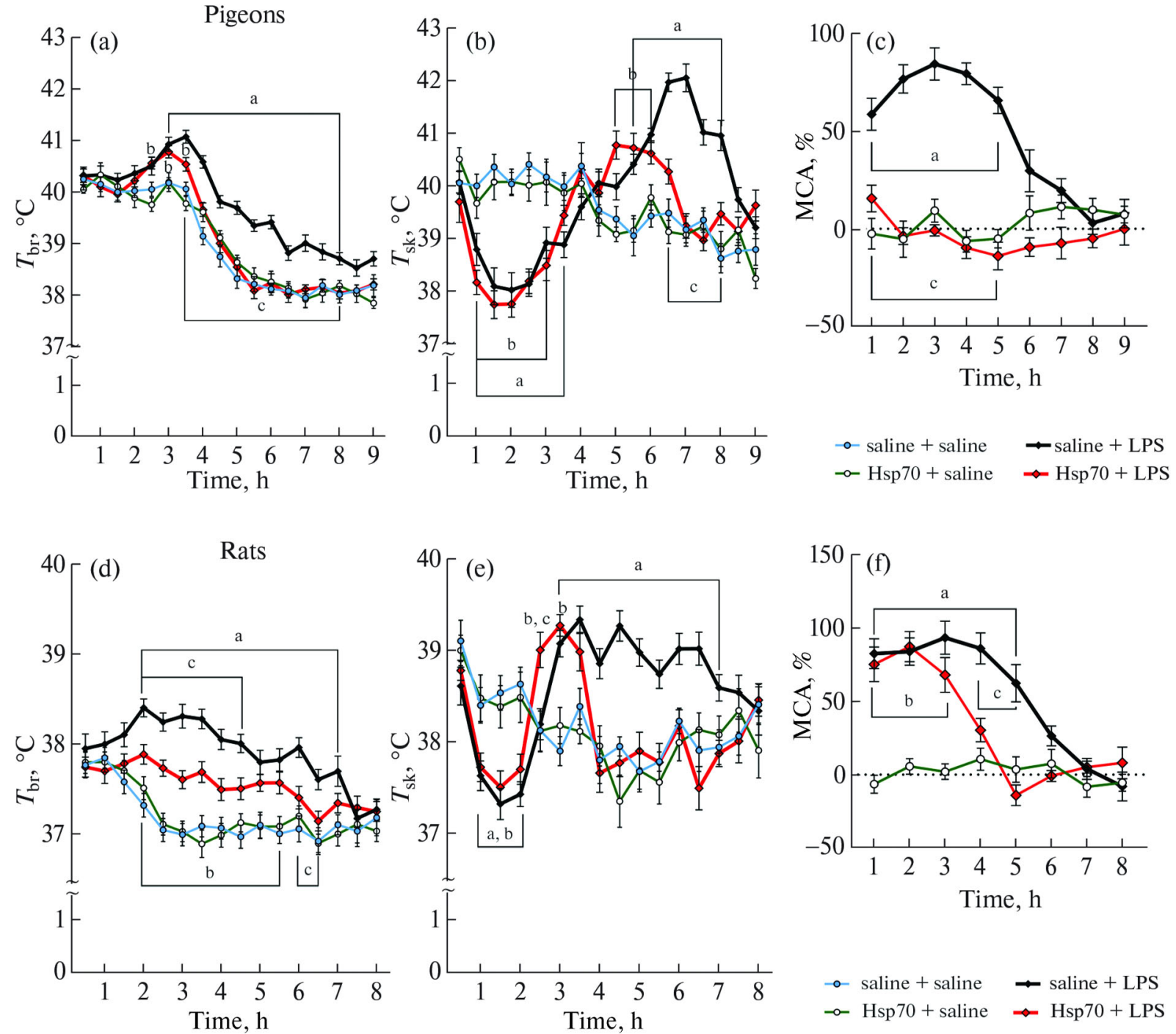

Fig. 1. Effect of Hsp70 on thermoregulation parameters during endotoxemia in pigeons (a-c) and rats (d-f). In (a), (b), (d) and (e): changes in brain temperature $\left(T_{\mathrm{br}}\right)$ and skin temperature $\left(T_{\mathrm{sk}}\right)$. Ordinate: $T_{\mathrm{br}}$ and $T_{\mathrm{sk}}$ values in control (saline + saline), upon the administration of Hsp70 (Hsp70+saline) and LPS (LPS+saline), and preventive Hsp70 administration before the induction of endotoxemia (Hsp70+LPS). Abscissa: time (h). (a) $F(3,20)=19.20, p<0.0001$; (b) $F(3,20)=3.855, p=0.0251$; (d) $F(3,20)=7.398, p=0.0016$; (e) $F(3,20)=5.855, p=0.0026$. In (c) and (f): changes in the level of muscle contractile activity (MCA) in pigeons and rats under the same exposures vs. control level. (c) $F(2,15)=314.3, p<0.0001$; (f) $F(2,15)=$ 334.3, $p<0.0001$. $^{\mathrm{a}} p<0.05$-significant difference of LPS effects vs. control; ${ }^{\mathrm{b}} p<0.05$-significant difference of effects of preventive Hsp70 administration before LPS administration vs. control; ${ }^{\mathrm{c}} p<0.05$-significant difference of LPS effects vs. effects of preventive Hsp70 administration before LPS administration.

purified from endotoxin using polymyxin-B, it was necessary to check for the presence of a residual LPS contamination, which could affect the results of the experiments. LPS is known to be resistant to high temperatures, and in order to exclude the possibility of its influence on the results of our study, an additional series of experiments was undertaken using Hsp70den. This reagent was subjected to heat, which caused denaturation and loss of Hsp70 activity, leaving the properties of the possible LPS contamination unaffected. Our experiments showed that i.v. Hsp70den administration had no effect on changes in thermoregulation parameters characteristic of endotoxemia (Figs. 2a-2f). These data indicate that the fever relief in pigeons and rats, 

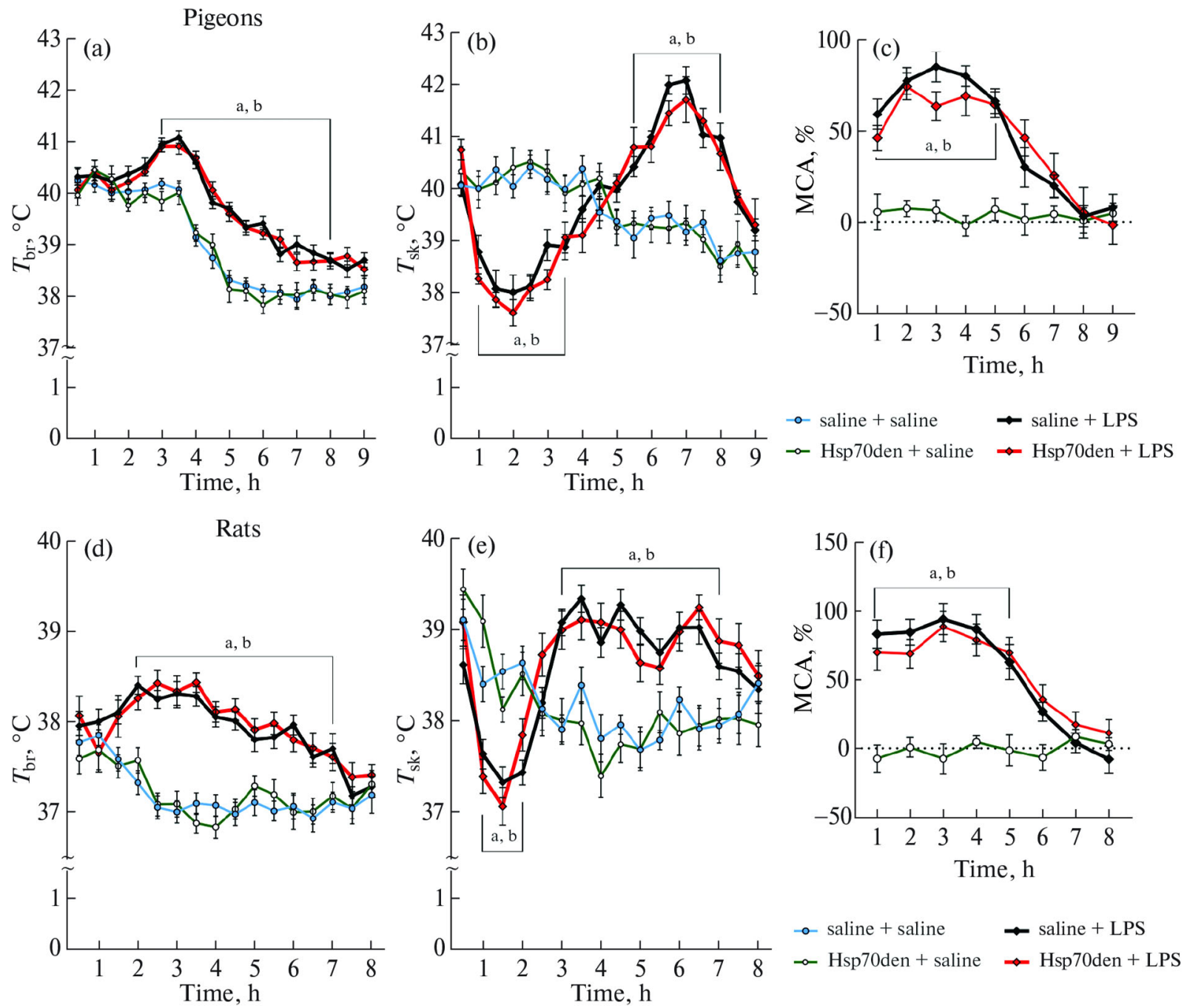

Fig. 2. Effect of Hsp70den on thermoregulation parameters during endotoxemia in pigeons (a-c) and rats (d-f). In (a), (b), (d) and (e): changes in brain temperature $\left(T_{\mathrm{br}}\right)$ and skin temperature $\left(T_{\mathrm{sk}}\right)$. Ordinate: $T_{\mathrm{br}}$ and $T_{\mathrm{sk}}$ values in control (saline+saline), upon the administration of thermodenaturated Hsp70 (Hsp70den+saline) and LPS (LPS+saline), and preventive administration of thermodenaturated Hsp70 before the induction of endotoxemia (Hsp70den+LPS). Abscissa: time (h). (a) $F(3,16)=18.14, p<0.0001$; (b) $F(3,16)=8.42, p=0.0014$; (d) $F(3,16)=10.32, p=0.0005$; (e) $F(3,16)=8.44, p=$ 0.0014 . In (c) and (f): changes in the level of muscle contractile activity (MCA) in pigeons and rats under the same exposures vs. control level. (c) $F(2,12)=210.1, p<0.0001$; (f) $F(2,12)=323.9, p<0.0001$. $^{\mathrm{a}} p<0.05$ - significant difference of LPS effects vs. control; ${ }^{b} p<0.05$ - significant difference of effects of preventive Hsp70den administration before LPS administration vs. control.

which resulted from the preventive Hsp70 administration, was an intrinsic effect of this reagent.

\section{Effect of Hsp 70 on white blood cell count during endotoxemia in rats}

Numerous studies indicate the ability of Hsp70 to modulate the functioning of immunocompetent cells. However, our experiments demonstrated that intravenous administration of exogenous Hsp70 does not cause significant changes in the number of WBCs either $1 \mathrm{~h}$ or $5 \mathrm{~h}$ post injection (Fig. 3a). LPS administration to rats caused an increase in the WBC count by $56 \%$ and $58 \%$ after $1 \mathrm{~h}$ and $5 \mathrm{~h}$, respectively (Fig. 3a). With the preventive Hsp70 administration, a decrease in the WBC count was observed after $1 \mathrm{~h}$ compared to the effect of LPS alone. After $5 \mathrm{~h}$, the values of this parameter reached the control level (Fig. 3a).

Our experiments showed that the administra- 

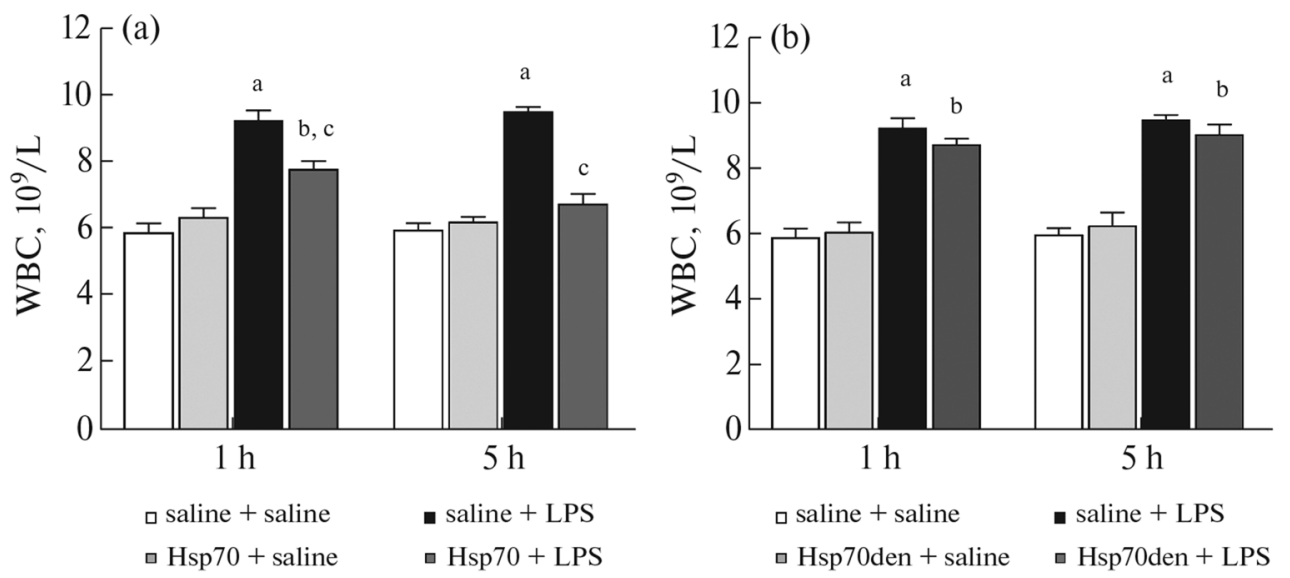

Fig. 3. Effect of Hsp70 and Hsp70den on the white blood cell (WBC) count in rats $1 \mathrm{~h}$ and $5 \mathrm{~h}$ after the induction of endotoxemia. (a) Changes in the WBC count in control (saline+saline), upon the administration of Hsp70 (Hsp70+saline), LPS (LPS+saline), and preventive Hsp70 administration before the induction of endotoxemia (Hsp70+LPS); (b) same in control (saline+saline), upon the administration of thermodenaturated Hsp70 (Hsp70den+saline), LPS (LPS+saline), and preventive administration of Hsp70den before the induction of endotoxemia (Hsp70den+LPS). (a) $F(3,28)=38.4, p<0.0001$ (after $1 \mathrm{~h}$ ), $F(3,28)=70.11, p<0.0001$ (after $5 \mathrm{~h}$ ); (b) $F(3,26)=48.2, p<0.0001$ (after $1 \mathrm{~h}$ ); $F(3,26)=50.1, p<0.0001$ (after $5 \mathrm{~h}$ ). ${ }^{\mathrm{a}} p<0.05$ - significant differences of LPS effects vs. control; ${ }^{\mathrm{b}} p<0.05$ - significant difference of effects of preventive Hsp70 or Hsp70den administration before LPS administration vs. control; ${ }^{\mathrm{c}} p<0.05$ - significant differences of LPS effects vs. effects of preventive Hsp70 or Hsp70den administration before LPS administration vs. control.

tion of Hsp70den did not cause a change in the WBC count, and its application before the induction of endotoxemia did not correct leukocytosis, which is characteristic of the effect of LPS (Fig. 3b). These data confirm that the ability of Hsp70 to attenuate LPS-induced leukocytosis, as revealed in this study, is an intrinsic property of exogenous Hsp70.

\section{DISCUSSION}

The endotoxin LPS is a widely used agent for modelling endotoxemia and studying changes in various thermoregulation parameters. Our study demonstrated that the administration of LPS in both pigeons and rats caused an increase in $T_{\mathrm{br}}$, accompanied by the development of vasoconstriction and an increase in the MCA level. Vasoconstriction is a peripheral vascular reaction aimed at limiting heat dissipation and promoting an increase in $T_{\mathrm{br}}$. The enhancement of MCA in endotoxemia represents a mechanism aimed at increasing heat production and promoting an increase in body temperature [6, 8]. The subsequent development of vasodilation, as observed in both pigeons and rats, may have been a mechanism limiting a further increase in $T_{\mathrm{br}}$. Thus, in our study, the development of endotoxemia in pigeons and rats was characterized by similar changes in thermoregulation parameters, which indicates the community of the thermoregulatory mechanisms underlying the response to endotoxin in pigeons and rats. The differences in this reaction to LPS between pigeons and rats consisted in the fact that the febrile response in rats developed earlier than in pigeons. In addition, the period of $T_{\mathrm{br}}$ elevation, as well as the periods of vasoconstriction and vasodilation, had different durations.

In our study, we performed for the first time a comparative physiological study of the effect of exogenous Hsp70 on the development of a febrile reaction in members of the two classes of vertebrates. Our experiments showed that in pigeons, Hsp70 administration reduced an increase in $T_{\mathrm{br}}$ and significantly accelerated its reversion to the control values. In rats, in contrast to pigeons, Hsp70 reduced the magnitude of the febrile response, but the increase in $T_{\text {br }}$ persisted longer than in pigeons. In both pigeons and rats, peripheral vasoconstriction persisted, but the subsequent phase of vasodilation was less pronounced, which may have been associated with a lower intensity of the febrile reaction. A more pronounced anti- 
pyretic effect of Hsp70 administration in pigeons is further evidenced by the absence of an increase in MCA, which probably contributed to a decrease in heat production. In contrast to pigeons, in rats, the increase in MCA persisted for $3 \mathrm{~h}$ after LPS administration. However, the restoration of this parameter to the control values occurred earlier than with the effect of LPS alone, and may have promoted a decrease in both heat production and $T_{\mathrm{br}}$. It can be assumed that a more pronounced antipyretic effect of $\mathrm{Hsp} 70$ in rat LPS-induced endotoxemia requires a higher dose of this protein agent.

We established that LPS administration led to the development of leukocytosis in rats. An increase in the number of WBCs is one of the hallmarks of the inflammatory process [39]. As early as $1 \mathrm{~h}$ after the preventive Hsp70 administration, we observed a decrease in the WBC count, while after $5 \mathrm{~h}$, this parameter normalized. Apparently, the decrease in WBC recruitment after the preventive Hsp70 administration may attest to antiinflammatory properties of Hsp70. Thus, our data indicate the ability of Hsp70 to correct thermoregulation parameters of the LPS-induced febrile response, as well as the inflammatory response, in both pigeons and rats.

The well-known major participants in the triggering of fever in endotoxemia are pro-inflammatory cytokines IL- $1 \beta$, IL- $6, \mathrm{TNF}-\alpha$, as well as a principal downstream mediator of fever prostaglandin $\mathrm{E}_{2}\left(\mathrm{PGE}_{2}\right)[6,40]$. However, the exact mechanisms behind the transmission of a LPS pro-inflammatory signal in birds remains obscure, since the bulk of studies devoted to this issue have been carried out on mammals. It is assumed that in birds, in contrast to mammals, IL-6 plays a more important role in triggering fever, while the involvement of $\mathrm{PGE}_{2}$ appears to be less pronounced [41]. It has been shown that exogenous Hsp70 can interact with receptor complexes of immunocompetent cell membranes (CD11b/ CD18, TLR2, TLR4) and modulate their activity. This leads to a decrease in the production of reactive oxygen species, TNF- $\alpha$, IL- 6 , expression of TLR4 on the membrane surface, and IL- $1 \beta$ mRNA level [42-45]. There is evidence that the anti-inflammatory effect of Hsp70 may also be due to the involvement of the anti-inflammatory cytokine IL-10 [46]. In in vivo experiments, it was found that preventive Hsp70 administration promotes an increase in the survival rate of animals upon the injection of high LPS doses, corrects a number of hemodynamic and biochemical parameters of blood (concentrations of bilirubin, creatinine, etc.) [28-31]. The totality of these data suggests that preventively administered Hsp70 can compete with LPS for binding to TLR2 and TLR4, while blocking the activation of the pro-inflammatory cascade with the involvement of the NF-kB factor. This assumption is supported by the data that the therapeutic application of Hsp70 (after the administration of a high dose of LPS) did not eliminate the development of tachycardia nor reduced the mortality rate [28]. It is well known that one of the key participants in the triggering of the febrile reaction is $\mathrm{PGE}_{2}$ produced by peripheral macrophages [6], and it seems likely that the ability of Hsp70 to interact with these cells leads to a decrease in $\mathrm{PGE}_{2}$ production and attenuation of the febrile response.

It should be noted that the above data on the protective effects of exogenous Hsp70 were obtained using cell cultures and laboratory mammals (mice and rats). The birds were found to have the same types of immunocompetent cells, as well as CD11b receptors and major mediators of inflammation (IL-6, IL-1 $\beta$, TNF- $\alpha, \mathrm{PGE}_{2}$ ) [47, 48]. Apparently, the antipyretic effect of Hsp70 in pigeons and rats could have been realized via the similar mechanisms, being a result of the effect on the functioning of immunocompetent cells and production of pro-inflammatory cytokines. There is an opinion that birds are more tolerant to the effect of LPS than mammals. The TLR4 complex was found in both birds and mammals. However, in birds, neither LPS-binding protein, nor the free form of the CD14 receptor involved in signal transduction in mammals, nor the TLR4-mediated signaling cascade ensuring the production of interferons were found [49, 50]. Probably, the more pronounced antipyretic effect of Hsp70 in pigeons is associated with this feature.

Thus, our study showed that Hsp70 administration reduces the magnitude of the febrile response to LPS in pigeons and rats, and also contributes to the normalization of the number of WBCs in the rat blood. These results indicate the ability of 
Hsp70 to attenuate the systemic inflammatory response. It can be assumed that mammals and birds, at least some of their representatives, share the common mechanisms of realization of the anti-inflammatory effect of Hsp70 during endotoxemia. The data obtained can provide a fundamental rationale for further research in this direction in order to assess the therapeutic potential of exogenous Hsp70 in endotoxemia and sepsis, which will be important for developing novel treatment strategies for these conditions.

\section{AUTHORS' CONTRIBUTION}

K.V.L.: conducting experiments, data processing and analysis, writing a manuscript; I.V.G.: obtaining Hsp70 protein, editing a manuscript; I.V.E.: conceptualization, experimental design, data analysis, editing a manuscript.

\section{FUNDING}

This work was implemented within a governmental assignment to the IEPhB (AAAA-A18H8012290427-7).

\section{CONFLICT OF INTEREST}

The authors assure that they have neither evident nor potential conflict of interest related to the publication of this article.

\section{REFERENCES}

1. Roth J, Blatteis CM (2014) Mechanisms of fever production and lysis: lessons from experimental LPS fever. Comp Physiol 4:1563-604. https:// doi.org/10T002/cphy.c130033

2. Evans SS, Repasky EA, Fisher DT (2015) Fever and the thermal regulation of immunity: the immune system feels the heat. Nat Rev Immunol 15:335-349. https://doi.org/10.1038/nri3843

3. Dickson K, Lehmann C (2019) Inflammatory response to different toxins in experimental sepsis models. Int J Mol Sci 20:4341. https://doi.org/ 10.3390/ijms20184341

4. Kluger MJ, Kozak W, Conn C, Leon L, Soszynski D (1996) The adaptive value of fever. Infect Dis Clin North Am 10:1-20. https://doi.org/10.1016/ S0891-5520(05)70282-8
5. Lapshina KV, Ekimova IV (2010) Effects of sleep deprivation on measures of the febrile reaction and the recovery of somatovisceral functions and sleep in endotoxemia. Neurosci Behav Physiol 40: 381-388. https://doi.org/10.1007/s11055-0109268-6

6. Nakamura K (2011) Central circuitries for body temperature regulation and fever. Am J PhysiolRegul Integr Comp Physiol 301: 1207-1228. https://doi.org/10.1152/ajpregu.00109.2011

7. Gray DA, Marais M, Maloney SK (2013) A review of the physiology of fever in birds. J Comp Physiol B Biochem Syst Environ Physiol 183:297312. https://doi.org/10.1007/s00360-012-0718-z

8. Garami A, Steiner AA, Romanovsky AA (2018) Fever and hypothermia in systemic inflammation. In: Handbook of Clinical Neurology. Elsevier B 157:565-597. https://doi.org/10.1016/B978-0444-64074-1.00034-3

9. Sundgren-Andersson AK, IJstlund P, Bartfai T (1998) Simultaneous measurement of brain and core temperature in the rat during fever, hyperthermia, hypothermia and sleep. Neuroimmunomodulation 5: 241-247. https://doi.org/10.1159/ 000026344

10. Ekimova IV (2003) Changes in the metabolic activity of neurons in the anterior hypothalamic nuclei in rats during hyperthermia, fever, and hypothermia. Neurosci Behav Physiol 33:455460. https://doi.org/10.1023/Ar1023459100213

11. Kiyatkin EA, Sharma HS (2009) Permeability of the blood-brain barrier depends on brain temperature. Neuroscience 161: 926-939. https://doi.org/ 10.1016Xj.neuroscience.2009.04.004

12. Gotoh M, Nagasaka K, Nakata M, Takashima I, Yamamoto S (2020) Brain temperature alters contributions of excitatory and inhibitory inputs to evoked field potentials in the rat frontal cortex. Front Cell Neurosci 14: 593027. https://doi.org/ 10.3389/fncel.2020.593027

13. Noorani AA, Yamashita $\mathrm{H}$, Gao $\mathrm{Y}$, Islam S, Sun Y, Nakamura T, Enomoto H, Zou K, Michikawa M (2020) High temperature promotes amyloid $\mathrm{P}$-protein production and $\mathrm{Y}$-secretase complex formation via $\mathrm{Hsp} 90$. J Biol Chem 295:18010-18022. https://doi.org/10.1074/ jbc.RA120.013845

14. Dube CM, Brewster AL, Baram TZ (2009) Febrile seizures: mechanisms and relationship to epilepsy. Brain Dev 31: 366-371. https://doi.org/ 10.1016/j.braindev.2008.11.010

15. Walter EJ, Carraretto M (2016) The neurological and cognitive consequences of hyperthermia. Crit Care 20:199. https://doi.org/10.1186/s13054- 
016-1376-4

16. Li H, Liu L, Zhang D, Xu J, Dai H, Tang N, Su X, Cao B (2020) SARS-CoV-2 and viral sepsis: observations and hypotheses. Lancet 395:15171520 . 6736(20)30920-X

17. Liu E, Lewis K, Al-Saffar H, Krall CM, Singh A, Kulchitsky VA, Corrigan JJ, Simons CT, Petersen SR, Musteata FM, Bakshi CS, Romanovsky AA, Sellati TJ, Steiner AA (2012) Naturally occurring hypothermia is more advantageous than fever in severe forms of lipopolysaccharideand Escherichia coli-induced systemic inflammation. Am J Physiol-Regul Integr Comp Physiol 302:13721383. https://doi.org/10.1152/ajpregu.00023.2012

18. Zhang YH, Takahashi K, Jiang GZ (1994) In vivo production of heat shock protein in mouse peritoneal macrophages by administration of lipopolysaccharide. Infect Immun 62(10): 4140-4144. https://doi.org/10.1128/IAI.62.10.41404144.1994

19. Meng X, Brown JM, AL, Nordeen SK, Franklin W, Harken AH, Banerjee A (1996) Endotoxin induces cardiac HSP70 and resistance to endotoxemic myocardial depression in rats. Am J Physiol 271:1316-1324. https://doi.org/10.1152/ ajpcell.1996.27L4.C1316

20. Sarson AJ, Read LR, Haghighi HR, Lambourne MD, Bris- bin JT, Zhou H, Sharif S (2007) Construction of a microarray specific to the chicken immune system: profiling gene expression in B cells after lipopolysaccharide stimulation. Can J Vet Res 71:108-118.

21. Zhang A, Zhou X, Wang X, Zhou H (2011) Characterization of two heat shock proteins (Hsp70/ Hsc70) from grass carp (Ctenopharyngodon idella): evidence for their differential gene expression, protein synthesis and secretion in LPS-challenged peripheral blood lymphocytes. Comp Biochem Physiol B Biochem Mol Biol 159:109114. https://doi.org/10.1016/j.cbpb.2011.02.009

22. Chiaramonte $M$, Inguglia $L$, Vazzana $M$, Deidun A, Arizza V (2019) Stress and immune response to bacterial LPS in the sea urchin Paracentrotus lividus (Lamarck, 1816). Fish Shellfish Immunol 92:384-394. https://doi.org/10.1016/ j.fsi.2019.06.017

23. Daugaard M, Rohde M, Jaattela M (2007) The heat shock protein 70 family: Highly homologous proteins with overlapping and distinct functions. FEBS Lett 581:37023710 https://doi.org/ 10.1016/j.febslet.2007.05.039

24. Rosenzweig R, Nillegoda NB, Mayer MP,
Bukau B (2019) The Hsp70 chaperone network. Nat Rev Mol Cell Biol 20: 665-680. https:// doi.org/10.1038/s41580-019-0133-3

25. Calderwood SK, Murshid A, Prince T (2009) The shock of aging: molecular chaperones and the heat shock response in longevity and aging-a minireview. Gerontology 55:550-558. https://doi.org/ $10.1159 / 000225957$

26. Srivastava P (2002) Interaction of heat shock proteins with peptides and antigen presenting cells: chaperoning of the innate and adaptive immune responses. Annu Rev Immunol 20:395-425. https://doi.org/10.1146/annurev.immunol.20.100301.064801

27. Asea A (2008) Heat shock proteins and toll-like receptors. Handb Exp Pharmacol. (183):111-127.

28. Kustanova GA, Murashev AN, Karpov VL, Margulis BA, Guzhova IV, Prokhorenko IR, Grachev SV, Evgen'ev MB (2006) Exogenous heat shock protein 70 mediates sepsis manifestations and decreases the mortality rate in rats. Cell Stress Chaperones 11: 276-286. https://doi.org/ 10.1379/csc-195r.1

29. Yurinskaya MM, Vinokurov MG, Zatsepina OG, Garbuz DG, Guzhova IV, Rozhkova EA, Suslikov AV, Karpov VL, Evgen'ev MB (2009) Exogenous heat shock proteins (HSP70) significantly inhibit endotoxin-induced activation of human neutrophils. Dokl Biol Sci 426:298-301. https:// doi.org/10.1134/s0012496609030326

30. Rozhkova EA, Yurinskaya MM, Zatsepina OG, Garbuz DG, Karpov VL, Surkov S, Murashev AN, Ostrov VF, Margulis BA, Evgen'ev MB, Vinokurov MG (2010) Exogenous mammalian extracellular HSP70 reduces endotoxin manifestations at the cellular and organism levels. Ann NY Acad Sci 94-107. https://doi.org/ 10.1111/j.1749-6632.2009.05375.x

31. Ostrov VF, Slashcheva GA, Zharmukhamedova TIu, Garbuz DG, Evgen'ev MB, Murashev AN (2010) Effect of the recombinant human heat shock protein HSP70 on the biochemical properties of blood in a model of endotoxic shock in rats. Bioorg Khim 36:337-342. https://doi.org/10.1134/ s1068162010030052

32. Pastukhov YF, Ekimova IV, Hudik KA, Guzhova IV (2005) Lipopolysaccharide-free 70-kDa heat shock protein has hypothermic and somnogenic effects. Dokl Biol Sci 402:167-170. https:// doi.org/10.1007/s10630-005-0077-y

33. Pastuhov YuF, Hudik KA, Ekimova IV (2010) Chaperones in regulation and restoration of physiological functions. Ros Fiziol Zh im IM Sechenova 96:708-725. (In Russ). 
34. Shevtsov MA, Nikolaev BP, Yakovleva LY, Dobrodumov AV, Dayneko AS, Shmonin AA, Vlasov TD, Melnikova EV, Vilisov AD, Guzhova IV, Ischenko AM, Mikhrina AL, Galibin OV, Yakovenko IV, Margulis BA (2014) Neurotherapeutic activity of the recombinant heat shock protein Hsp70 in a model of focal cerebral ischemia in rats. Drug Des Devel Ther 8:639-650. https://doi.org/10.2147/DDDT.S62024

35. Ekimova IV, Plaksina DV, Pastukhov YF, Lapshina KV, Lazarev VF, Mikhaylova ER, Polonik SG, Pani B, Margulis BA, Guzhova IV, Nudler E (2018) New HSF1 inducer as a therapeutic agent in a rodent model of Parkinson's disease. Exp Neurol 306:199-208. https://doi.org/ 10.1016Xj.expneurol.2018.04.012

36. Karten HJ, Hodos W (1967) A stereotaxic atlas of the brain of the pigeon (Columba livia). Johns Hopkins Press, Baltimore. Maryland.

37. Paxinos G, Watson C (2007) The rat brain in stereotaxic coordinates. 6th Edition, Academic Press, San Diego.

38. Rashotte M, Pastukhov IuF, Poliakov E, Henderson R (1998) Vigilance states and body temperature during the circadian cycle in fed and fasted pigeons (Columba livia). Am J Physiol 275:1690$1702 . \quad$ https://doi.org/10.1152/ajpregu.1998.275.5.R1690

39. Ronco C, Piccinni P, Rosner MH (eds) (2010) Endotoxemia and endotoxin shock: disease, diagnosis and therapy. Contrib Nephrol Basel Karger (167): 1424.

40. Krueger JM, Opp MR (2016) Sleep and microbes. Int Rev Neurobiol 131:207-225. https://doi.org/ 10.1016/bs.irn.2016.07.003

41. Grabbe N, Kaspers B, Ott D, Murgott J, Gerstberger R, Roth J (2020) Neurons and astrocytes of the chicken hypothalamus directly respond to lipopolysaccharide and chicken interleukin-6. J Comp Physiol B 190:75-85. https://doi.org/ 10.1007/s00360-019-01249-1

42. Antonova OY, Yurinskaya MM, Evgen'ev MB, Vinokurov MG (2013) The role of the TLRdependent signaling pathway in the mechanism of phagocyte protection by exogenous heat shock protein HSP70 from the endotoxin action. Dokl Biol Sci 452:305-309. https://doi.org/10.1134/ S0012496613050037

43. Vinokurov M, Ostrov V, Yurinskaya M, Garbuz D, Murashev A, Antonova O, Evgen'ev M
(2012) Recombinant human Hsp70 protects against lipoteichoic acid-induced inflammation manifestations at the cellular and organismal levels. Cell Stress Chaperones 17:89-101. https:// doi.org/10.1007/s12192-011-0288-0

44. Ferat-Osorio E, Sánchez-Anaya A, GutiérrezMendoza M, Boscó-Gárate I, Wong-Baeza I, Pastelin-Palacios R, Pedraza-Alva G, Bonifaz LC, Cortés-Reynosa P, Prnez-Salazar E, Arriaga-Pizano L, López-Macias C, Rosenstein Y, Isibasi A (2014) Heat shock protein 70 down-regulates the production of toll-like receptor-induced pro-inflammatory cytokines by a heat shock factor-1/constitutive heat shock element-binding factor-dependent mechanism. Inflamm (Lond) 11:19. https://doi.org/10.1186/ 1476-9255-11-19

45. Yurinskaya MM, Kochetkova OYu, Shabarchina LI, Antonova OYu, Suslikov AV, Evgen'ev MB (2017) Encapsulated Hsp70 decreases endotoxin-induced production of ROS and TNFa in human phagocytes. Cell Stress Chaperones 22:163-171. https://doi.org/10.1007/ s12192-016-0743-Z

46. Borges TJ, Lopes RL, Pinho NG, Machado FD, Souza AP, Bonorino C (2013) Extracellular Hsp70 inhibits pro-inflammatory cytokine production by IL-10 driven down-regulation of C/EBPP and C/EBP5. Int J Hyperthermia 29:455-463. https:// doi.org/10.3109/02656736.2013.798037

47. Qureshi MA, Heggen CL, Hussain I (2000) Avian macrophage: effector functions in health and disease. Dev Comp Immunol 24:103-119. 2000. https://doi.org/10.1016/s0145-305x(99)00067-1

48. Rohde F, Schusser B, Hron T, Farkasova H, Plachy J, Hartle S, Hejnar J, Elleder D, Kaspers B (2018) Characterization of chicken tumor necrosis factor-a, a long missed cytokine in birds. Front Immunol 9:605. https://doi.org/10.3389/ fimmu.2018.00605

49. Brownlie R, Allan B (2011) Avian toll-like receptors. Cell Tissue Res 343:121-130. https://doi.org/ 10.1007/s00441-010-1026-0

50. Keestra AM, de Zoete MR, Bouwman LI, Vaezirad MM, van Putten JP (2013) Unique features of chicken Toll-like receptors. Dev Comp Immunol 41:316-323. j.dci.2013.04.009 https://doi.org/10.1016/

Translated by A. Polyanovsky 